\title{
Research on the influence mechanism of China's industrial circulation on long-term interest rate: Empirical analysis based on VEC model
}

\author{
Qiao Han ${ }^{1}$, Yang Jiayun ${ }^{2, *}$ \\ ${ }^{1}$ School of economics and management, Inner Mongolia Normal University, Hohhot, Inner Mongolia, China \\ ${ }^{2}$ School of economics and management, Inner Mongolia Normal University, Hohhot, Inner Mongolia, China
}

\begin{abstract}
As the adjustment space of China's monetary policy is gradually expanding and the adjustment intensity is gradually increasing, the influence of external factors on money supply and demand is gradually weakening. The endogenous mechanism of interest rate in the real economy needs to be further explored. Through the long-term interest rate model, the paper reveals the relationship between the circulation status of real economy and long-term interest rate. Based on the monthly data of China from 2003 to 2019, the paper establishes the error-correction VEC model and the state-space model to conduct empirical test and analysis on the influence mechanism of long-term interest rate. The final results show that exogenous factors such as monetary policy have certain influence on interest rate in the short run, while in the long run, interest rate is affected by the average circulation of goods described by the inventory increment of manufacturers and the actual production input of enterprises.
\end{abstract}

\section{Literature review}

Money supply and demand determine interest rate, and the endogenous and external nature of interest rate essentially depends on the endogenous and external nature of money supply and demand.

Mishkin (1995) believes that monetary policy can respond to national demand quickly, only if it is quickly transmitted to the market interest rate. It can be seen that the decision of interest rate actually depends on the supply and demand of money. Therefore, the decision of interest rate is actually determined by the supply and demand of money. From the perspective of macro economy, the discussion on the externality of interest rate is mostly based on the transaction function of money ${ }^{1}$. Liang Dongli (2009), from the perspective of central bank, believes that the externality of money supply mainly depends on two levels. The first level is whether the central bank can control the base money when the money multiplier is unchanged. Whether the central bank can control the money multiplier while the base money remains constant. The second level is whether the monetary policy of the central bank can effectively change the interest rate, so as to promote the change of effective demand, and then meet the demand for transaction money ${ }^{2}$. Zou Wenli (2019) believes that with the influence of market environment, the exogenicity of money supply is gradually highlighted, monetary policy is gradually changing from quantitative tool to price tool, and the central bank's adjustment of interest rate can be divided into direct influence mechanism and indirect influence mechanism. The direct influence mechanism will directly change the short-term interest rate, and the indirect influence mechanism will affect the medium - and long-term interest rate, lead to the change of total output, and ultimately affect the interest rate level ${ }^{3}$. Ma fang fang (2009) from the assets of preference of the social public endogenous research interest rates, in the money supply endogenous theory framework, by choosing preferences reflect the money demand and the social public assets variables, the basis of the conclusion, the paper found the issue with the current money supply has significant positive correlation, gross domestic product (GDP) and the consumer price index, and this positive correlation between money supply and cash leakage rate and the current money supply is negatively related. He believes that the endogenous transmission process of interest rate with money as the main body is: central bank - commercial banks enterprises and residents ${ }^{4}$. From the perspective of interest rate marketization, Huang Jing (2020) proposed that when the interest rate is not completely endogenous, China should actively encourage bank credit to play the role of financing, state-owned banks should actively support credit in key areas, and effectively weigh the impact of macroeconomic factors under the consideration of a certain limit of free floating interest rate, so as to better promote growth and curb inflation ${ }^{5}$.

In the evolution of modern economics, most scholars have studied the internal and exogenous causes of interest rates from the perspective of money supply. Zhou Liping (2013) took Keynesianism as the cut-off point and discussed the endogeneity and exophyity of money supply in different periods, so as to analyze its influence on

\footnotetext{
$\overline{{ }^{*} \text { Corresponding author: mzlyjy@163.com }}$
} 
endogeneity and exophyity of interest rate. The debate before Keynesianism focused on the nature of money and the determination of its value, which was the foundation of the debate between endogenous and exogenous money supply in modern times. The debate after Keynesianism mainly focused on the endogeneity of interest rate from the perspective of money supply. Keynesian theory of money supply endogenous including levels after socialist theory, structuralism, circulation, they think money demand in the financial market determines the central bank, the money supply, Davidson, from the perspective of the portfolio, that money supply is endogenous, thinks that there are endogenous financing needs, money is in the nature of capital, has the function of production, so the money supply is based on the real economy needs, is an endogenous, after but the Keynesian monetary demand into the internal and external influence interest by nature ${ }^{6}$. Yuan Hui (2021), in the horizontal theory's reconstruction of Keynesian monetary thought, proposed that the supply of credit money comes from the financing demand of economic subjects, and interest rate is the exogenous variable set by the monetary authority and the main monetary policy too ${ }^{7}$. Gracjan Robert Bachurewicz (2019) from the perspective of the money supply to the same after keynesianism to explore, in Poland, for example, using the method of granger causality test based on the analysis over the past 15 years the polish money supply endogenous problems, found that bank credit demand will also result in changes of the monetary base, lead to changes in bank deposits and money supply ${ }^{8}$.

From the perspective of the dual determination of interest rate, Zeng Xianjiu (2001) believed that interest rate has the dual nature of endogeneity and exogenity, and made a dialectical analysis of the relationship between the two. He believed that endogeneity of interest rate meant that interest rate was the price of capital and a reward for lending capitalists to transfer the right to use capital, while interest was a derivative form of interest rate and represented surplus value. Marx believed that interest rate was determined by profit, capital supply and demand, production cycle and other factors. In Das Kapital, Marx comprehensively demonstrated the decisive role of interest rate in economy. While considering the role of the two, the dual attributes are not equally distributed in the same interest rate body, but each interest rate has some main attributes. For example, when the central bank sets the official interest rate, it is exogenous, but the endogeneity of the interest rate should be taken into account when making the official interest rate, and the real economic situation should be considered. Therefore, the completely exogenous or completely endogenous interest rate does nothing. Therefore, the endogeneity and exogenity of the interest rate are dialectically unified ${ }^{9} . \mathrm{Li}$ Jianjian (2008) believes that interest rate is a dialectical unity of endogeneity and exophyity. The endogeneity of interest rate lies in that the interest rate is determined by both supply and demand in the market, which fully reflects the market situation. The exogenous nature of interest rates is that monetary authorities cause interest rates to be influenced by external forces. Only the full combination of the two can promote economic development together ${ }^{10}$.
Tu Chuanjun (2011) discussed the theory of internal and external generation of money supply. In his book Monetary Theory, Lauren Harris proposed that money supply is regulated by the central bank in order to stabilize employment and ensure output according to changes in the demand for transacted money caused by changes in income level. The money supply may also be caused by changes outside the economic system, which should be studied by experience. The internal and external symbiosis of interest rate is mainly affected by multiple factors outside the money supply system ${ }^{11}$.

Before the emergence of endogenous money theory, the research on the exogenicity of interest rate has experienced a long and tortuous development process, from the exogenicity of money supply to the endogeneity of money supply, from money demand to the occurrence of credit loans, and the research mainly takes the bank as the research object, such as investment, saving as a core variable, based on the theory of the IS - LM model .Previous studies hold that the interest rate itself is not based on any existence, but is externally qualitative. The interest rate changes according to the actual situation of money supply and demand. By taking the real economy as the scope, this paper will deeply explore the endogenous formation mechanism of interest rate, take the inventory increment of manufacturers and the production input of enterprises as the research object, and establish the interest rate determination mechanism model of endogenous money supply and demand in the long term. At the same time, the influence of industrial circulation on money supply and demand and the degree of response to monetary policy are analyzed through theoretical model and empirical study, so as to study a series of transmission processes of the ectogenicity determination mechanism of interest rate.

\section{2 theoretical model}

As credit creation is playing an increasingly important role in contemporary society, financial derivatives have become an important source of funds. Enterprises of manufacturing can carry out financing through a variety of forms. After credit creation, enterprises of manufacturing gradually adopt a series of diversified financing methods such as bonds and stocks. At the same time, in order to actively expand their business, the major banks continue to meet the needs of consumers through credit cards and other ways, and the credit system continues to expand.

With the continuous growth of consumer demand, the demand for money is also gradually increasing. The development of online trading system has led to the continuous emergence of online lending platforms, such as Ant Huabei. In fact, the monetary demand and the credit creation system are symbiotic, and the two show endogenous consistency for a long time. As the demand for manufacturing continues to expand, it proves to be the demand for money. First of all, the purchase of factors of production needs to cost part of monetary capital. It basically includes the input of the element such as raw materials, labor forces and fixed asset depreciation. Secondly, since interest is generated when borrowing from 
banks and other financial institutions, interest, as a debt repayment production input, also needs to cost part of monetary capital. Therefore, this paper builds a theoretical model based on the demand for money and money supply from the perspective of manufacturers.

A firm's demand for money depends on the input of each period of prepaid capital, $L_{t}=C A_{t}$, in which the input of each period of prepaid capital is represented as constant capital and variable capital. The supply of money comes from the sale of goods in each period, $M_{t}=S A_{t}$.

Because the manufacturers will have an imbalance of payments in a certain period of time, for each individual, $L_{t} \neq M_{t}$, becomes normal. Due to the surplus of the production and sales links, the enterprise will use part of the capital to maintain its normal operation, and the rest can be saved or invested. At this time, the bank and other financial institutions will carry out a new round of financing.

Therefore, although there is a currency imbalance at this time, it is only short-term and local in fact, and does not exist in the whole market. In terms of the long-term equilibrium point of view, the money market is still in equilibrium. In a certain period of time, due to the influence of some factors, the supply is greater than the demand, the growth of the number of goods is greater than the number of input of commodity production factors, the sales of commodity circulation is in a favorable stage, and the interest rate drops. When the supply is less than the demand, the circulation of goods is in a worsening stage, and interest rates rise.

A long-term interest rate equation is created as: $r_{t}=$ $f\left(\Gamma_{t}\right)$,where $\Gamma_{t}$ is the measure of the circulation at time $\mathrm{t}: \Gamma_{t}$ $'=\frac{L_{t}-M_{t}}{L_{t}}=\frac{C A_{t}-S A_{t}}{C A_{t}}=a_{t}$

Where $C A_{t}$ is the input of prepaid capital of the enterprise, and $S A_{t}$ is the sales volume.

According to the property of function, it can be obtained: $r_{t}^{\prime}=f^{\prime}\left(\Gamma_{t}\right)=f\left(\Gamma_{t}\right)=f\left(a_{t}\right)=\alpha+\beta a_{t}+\varepsilon_{t}$,

$a_{t}=\frac{C A_{t}-S A_{t}}{C A_{t}}$. When $\Gamma_{t}>0, C A_{t} .>S A_{t}, \quad r_{t}$ goes up, so the antiderivative is increasing, $\beta>0$, if $a_{t}$ is product output.

The result will be: $a_{t}=\frac{C A_{t}-Q_{t}+Q_{t}-S A_{t}}{C A_{t}}=1-\frac{Q_{t}}{C A_{t}}+$ $\frac{Q_{t}-S A_{t}}{C A_{t}}=1-\frac{Q_{t}}{C A_{t}}+\frac{\Delta C_{t}}{C A_{t}}$, where $\Delta C_{t}$ is represented as inventory, and $\Delta C_{t}$ is the inventory increment that is equal to current production minus sales. If $\frac{\Delta C_{t}}{C A_{t}}=a_{1} t$, The current output $Q_{t}=b\left(1+\pi_{T-1}, r\right) C A_{T-1}$, where $((1+$ $\left.\pi_{T-1}, r\right)$ is inflation; $C A_{T-1}$ is Capital investment of the previous period. $\mathrm{b}$ is assumed to be a constant,

$\frac{Q_{T}}{C A_{T}}=\frac{b\left(1+\pi_{T-1}, r\right) C A_{T-1}}{C A_{T}}=\lambda\left(1+\pi_{T}\right) a_{2 T}^{-1}, \quad a_{2 T}=\frac{C A_{T}}{C A_{T-1}}$, $\lambda=f(b, t)$

The result will be: $r_{t}^{\prime}=\alpha+\beta a_{t}+\varepsilon_{t}=\alpha+\beta\left(a_{1} t+\right.$ $\left.1-\lambda\left(1+\pi_{t}\right) a_{2 T}^{-1}\right)+\varepsilon_{t}=\alpha+\beta\left(a_{1} t\right)-\lambda \beta(1+$ $\left.\pi_{t}\right) a_{2 T}^{-1}+\varepsilon_{t}$

Assume that the firm's current production input is equal to fixed asset investment plus labour wages. $C A_{t}=$ $F A_{t}+W_{t}=C A_{T}^{\text {Pre }}$, where $F A_{t}$ is investment in fixed assets; $W_{t}$ for wages.
The result will be: $a_{1 T}=\frac{\Delta C_{t}}{C A_{t}^{\text {pre }}}=a_{1 T}=\frac{C A_{T}^{\text {pre }}}{C A_{T-1}^{\text {pre }}}$.

\section{3 empirical analysis}

The monthly data of China from 2003 to 2019 were selected for empirical analysis. Month-on-month CPI inflation is expressed as $\pi$;Yields on Chinese one-year government bonds. Total wages of industrial employees and total investment in industrial fixed assets (the sum of the two) are expressed as $C A_{t} ;$ Ending industrial inventory of goods as $\Delta C_{t}$. Data were revealed on the National Bureau of Statistics website and estimated using Eviews8.0. The model equation shows following: $y=$ $r^{\prime}=c+a X_{1}(t)+b X_{2}(t)+\varepsilon(t)$.

$$
\begin{aligned}
& X_{1}(t)=a_{1 T}=\frac{\Delta C_{t}(t)}{C A_{t}^{\text {pre }}(t)}, X_{2}(t)=(1+\pi(t)) a_{2}(t)^{-1}= \\
& (1+\pi(t)) \frac{C A_{T}^{\text {pre }}(t-1)}{C A_{T-1}^{\text {pre }}(t)}, b=-\lambda \beta, c=\alpha+\beta
\end{aligned}
$$

In the theoretical model, the production and sales of goods affect the interest rate through the endogenous money supply and demand rules. In reality, the interest rate can also affect the production and sales of goods through investment and consumption. Firstly, ADF test is adopted to test the unit root of variables, so as to describe the dynamic relationship between variables through the VAR model. In this ADF test, variables $\mathrm{y}, X_{1}$ and $X_{2}$ are all horizontally stable. The results of ADF test are shown in Table 1:

Table1. Unit root test

\begin{tabular}{|c|c|}
\hline Variable & $\begin{array}{c}\text { ADF Test } \\
\text { Statistical Test }\end{array}$ \\
\hline $\mathrm{y}$ & -0.08594 \\
& $(0.0026)$ \\
\hline$X_{1}$ & -0.9885 \\
& $(0.0000)$ \\
\hline$X_{2}$ & 1.9881 \\
& $(0.0000)$ \\
\hline
\end{tabular}

In ADF test, Prob of all variables are less than 0.05, variables y, $X_{1}$ and $X_{2}$ are all horizontally stable. We can build a VAR model. First of all, the variables are dimensionless. The following is the dimensionless processing process for $\mathrm{y}, X_{1}$, and $X_{2}: s t y_{n}=\frac{y_{n}-y_{\min }}{y_{\max }-y_{\min }}$;

$$
\begin{aligned}
& s^{2 t} x_{1 n}=\frac{x_{1 n}-x_{1 \min }}{x_{1 \max }-x_{1 \min }} ; \\
& s t x_{2 n}=\frac{x_{2 n}-x_{2 \min }}{x_{2 \max }-x_{2 \min }} .
\end{aligned}
$$

The VAR model was established. After examining the AIC lag length standard, the lag length of the model was selected as three phases. First, the unconstrained VAR model was used to see the significance of the results. The results of significance test are unexpected, and part of the coefficients $\mathrm{T}$ and $\mathrm{R}$ are not significant, so there may be long-term constraints. Since the variables are all stationary series, the co-integration test can be conducted, and the test results are shown in Table 2 below: 
Table2. Cointegration test

\begin{tabular}{|c|c|c|c|c|}
\hline $\begin{array}{c}\text { Number of } \\
\text { null } \\
\text { hypothesis } \\
\text { co- } \\
\text { integration } \\
\text { equations }\end{array}$ & $\begin{array}{c}\text { Eigenv } \\
\text { alue }\end{array}$ & $\begin{array}{c}\text { The } \\
\text { critical } \\
\text { value } \\
\mathbf{( 1 \%} \\
\text { significa } \\
\text { nce) }\end{array}$ & $\begin{array}{c}\text { The } \\
\text { critical } \\
\text { value } \\
\mathbf{( 5 \%} \\
\text { significa } \\
\text { nce) }\end{array}$ & $\begin{array}{c}\text { Likeliho } \\
\text { od } \\
\text { Ratio }\end{array}$ \\
\hline 0 & 0.5727 & 35.65 & 29.58 & 301.1759 \\
\hline 1 & 0.4675 & 20.04 & 15.41 & 131.1281 \\
\hline 2 & 0.0251 & 6.65 & 3.76 & 5.0940 \\
\hline
\end{tabular}

According to the test results, there is only one cointegration relationship between the three variables, and the number of co-integration vectors is less than the number of variables, so it is necessary to add the error correction model VEC model for estimation. According to the model estimation results, the VEC model has a good fitting property, and the $\mathrm{T}$ value of the related major variables is tested significantly in the confidence interval of $90 \%$, as shown in Table 3 below:

Table3. VEC error correction model

\begin{tabular}{|c|c|c|c|}
\hline & $\begin{array}{c}\text { Estimato } \\
\mathbf{r}\end{array}$ & $\begin{array}{c}\text { Standard } \\
\text { eviation }\end{array}$ & T statistic \\
\hline CointEq1 & -0.0028 & 0.00192 & -1.47051 \\
\hline $\mathrm{D}($ STY(-1)) & 0.2086 & 0.07200 & 2.89769 \\
\hline $\mathrm{D}($ STY(-2)) & -0.058 & 0.07351 & -0.07848 \\
\hline $\mathrm{D}($ STY(-3)) & -0.1121 & 0.07230 & -1.55035 \\
\hline $\mathrm{D}($ STX1(-1)) & -0.0340 & $(0.07323)$ & -0.46442 \\
\hline $\mathrm{D}($ STX1(-2)) & 0.02034 & 0.08482 & 0.23975 \\
\hline $\mathrm{D}($ STX1(-3)) & -0.0835 & 0.07331 & -1.13846 \\
\hline $\mathrm{D}($ STX2(-1) & 0.0745 & 0.08024 & 0.92832 \\
\hline $\mathrm{D}($ STX2(-2) $)$ & 0.0370 & 0.05796 & 0.63797 \\
\hline $\mathrm{D}($ STX2(-3)) & 0.01947 & 0.03662 & 0.53125 \\
\hline
\end{tabular}

\section{$R^{2}=0.84737, \overline{R^{2}}=0.036311, \mathrm{~F}=1.749813$}

According to the $\mathrm{y}$ of the pulse response of $X_{1}$ and $X_{2}$ respectively, in the first place when the inventory incremental ratio increases the $X_{1}$, dy dropped to 2 interval first, then quickly rose to the third interval, and quickly fell down to the fourth interval, within the range of 5 to start the relatively gentle fluctuation, fall within the range of 8, 9 range from then began rising, achieve smooth. And in view of the impact on $X_{2}$, dy significantly decreased to 3 interval, then dy due to inflation in the third interval appeared rose slightly, then decreasing due to the current production capital, leading to the endogenous monetary demand is greater than exogenous money demand, dy dropped to sixth interval, then rose to 7 interval, reached a stable within the range of 8.It can be seen that for the impulse response of Y to $X_{1}$ and $X_{2}$, the inventory ratio increases ( $X_{1}$ increases); In the long run, the increase of production capital input $\left(X_{2}\right.$ decrease) can have a positive impact on the increment of interest rate. See Figure 1 below:
Response of STY to One S.D. STX1 Innovation
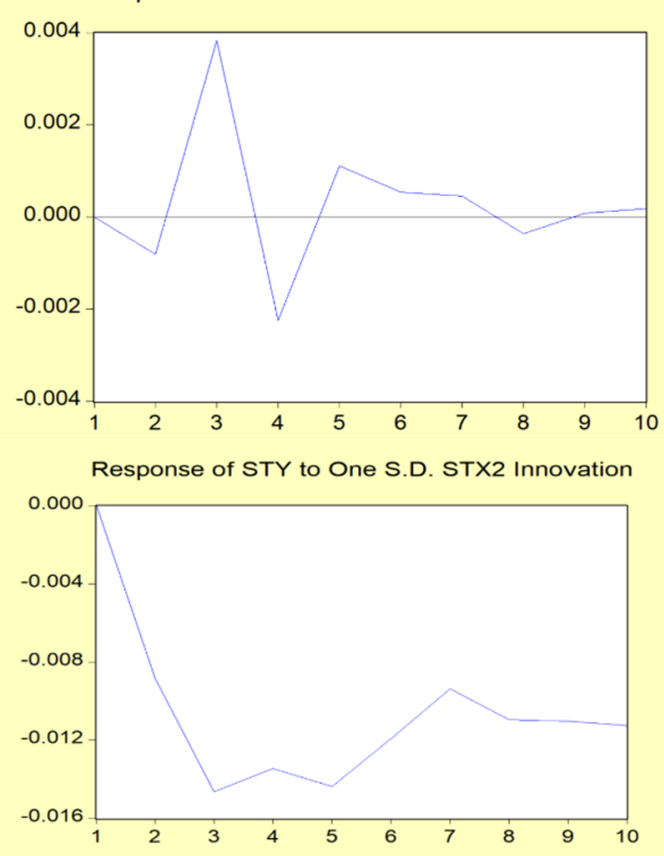

Fig 1. Response of STY to One S.D. STX Innovation

In the long run, the coefficient of influence on $\mathrm{y}$ is positive, and the coefficient of influence on $y$ is negative. It is roughly consistent with the direction of coefficient prediction of A and B in the theoretical model. From the perspective of impulse response, exogenous factors have temporary effects on interest rate, while endogenous shocks of actual economic circulation will have long-term effects on interest rate, which is in line with the conclusion set by the theoretical model. According to various tests, although there is one cointegration equation and VEC has conducted error correction test, it is found that although autocorrelation can be rejected, heteroscedasticity cannot be rejected, indicating that important variables are missing in this model. This may be caused by the following reasons: First, because this paper is based on the assumption of constant productivity, product factor input rate and product output rate, which are contradictory to the reality. Secondly, due to the continuous emergence of financial innovations and other exogenous factors, the connotation of circulation has changed. In order to study the dynamic characteristics of the influence of circulation condition on interest rate more comprehensively, the state space model can be introduced to estimate it, and the state variables that are difficult to be observed in practice can be included in the observable model to analyse the change trend of the relationship between the variables. After relevant premise tests and other calculations, the statespace model measurement can be established. The measurement method is as follows:

$$
\begin{gathered}
s t y=c(1)+s v_{1} * s t x_{1}+s v_{2} * s t x_{2}+[\text { ename }] \\
=e_{1}, \operatorname{var}=\operatorname{ecp}(c(2)) \\
s v_{1}=s v_{1}(-1) ; s v_{2}=s v_{2}(-1)
\end{gathered}
$$

The estimated results are shown in Table 4 below: 
Table4. Estimation results of state space model

\begin{tabular}{|c|c|c|c|c|}
\hline & $\begin{array}{c}\text { Number of } \\
\text { null } \\
\text { hypothesis } \\
\text { co- } \\
\text { integration } \\
\text { equations }\end{array}$ & $\begin{array}{c}\text { Standard } \\
\text { eviation } \\
\text { statistic }\end{array}$ & Prob \\
\hline $\mathrm{C}(1)$ & 0.545 & 0.064 & 8.564 & 0.000 \\
\hline $\mathrm{C}(2)$ & -3.518 & 0.180 & -19.536 & 0.000 \\
\hline & $\begin{array}{c}\text { Final state } \\
\text { vector }\end{array}$ & RMSE & $\begin{array}{c}\mathbf{Z} \\
\text { statistic }\end{array}$ & Prob \\
\hline$s v_{1}$ & 0.260 & 0.176 & 1.477 & 0.140 \\
\hline$s v_{2}$ & 0.174 & 0.071 & 2.436 & 0.015 \\
\hline \multicolumn{2}{|c|}{ Maximum likelihood } \\
value & 11.179 & & \\
\hline \multicolumn{2}{|c|}{ Schwarz criterion } & 0.072 & & \\
\hline \multicolumn{2}{|c|}{ Hannan-Quinn criter. } & -0.161 & & \\
\hline \multicolumn{2}{|c|}{ Parameters } & 2 & & \\
\hline \multicolumn{2}{|c|}{ Diffuse priors } \\
criterion
\end{tabular}

It can be seen from the results that the corresponding state vector test of the variable is not significant, but the corresponding state vector test is significant. The changes in different time periods are further investigated. See Figure 2 below:

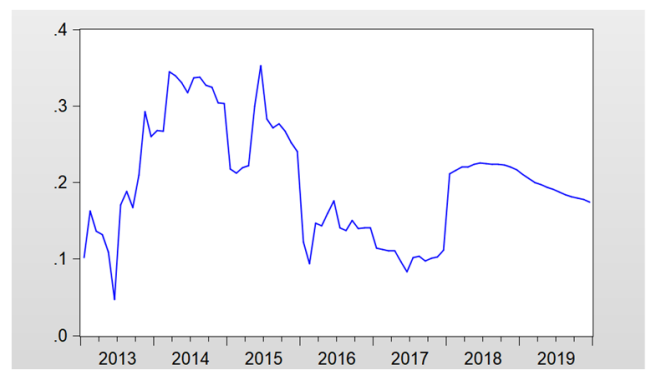

Fig 2. Plus image

From the point of the time series of state variables, in the past six years, the enterprise production cost of the current period into the reaction coefficient of the ups and downs, but because our country monetary policies change more frequently since 2015 , during the period of 20152017, the People's Bank of China cut RMB loan and deposit rates in many financial institutions, in order to further reduce the enterprise financing costs, China's economy the influence of exogenous intervention factors occupy the dominant positions, the actual circulation status of relative influence on interest rates, increasingly sharp, but its rebound from the 2017 years, beginning in 2018 our China's country money market rates overall goes downward, The medium - and long-term liquid supply is gradually enhanced. The coefficient tends to rise steadily and fluctuates within the range of 2.0, indicating that the effectiveness of exogenous conflict intervention has gradually weakened in the past two years.

\section{Conclusion}

The long-term interest rate model reveals the internal relationship between the circulation status of the real economy and the long-term interest rate. Taking the data of China from 2003 to 2019 as an example, this paper conducts an empirical analysis on the influence mechanism of the long-term interest rate by constructing the error-corrected VEC model and the state-space model. The results show that exogenous factors such as monetary policy have a certain influence on interest rate in the short run, while in the long run, interest rate is affected by the average circulation of goods described by the inventory increment of manufacturers and the actual production input of enterprises. According to the observation of the model, it is found that the influence mechanism of longterm interest rate described in the model is weakened due to the expansionary monetary policy adopted in China in recent years, the increasing innovation types of financial derivatives, and the diversification of electronic payment and overseas payment methods. According to the parameter analysis, after the people's Bank of China lowered the benchmark interest rates of RMB loans and deposits of financial institutions, the influence mechanism of money supply and demand interest rates determined by the circulation of the real economy gradually expanded.

\section{References}

1. F.Mishkin, Symposium on the Monetary Transmission Mechanism. Journal of Economic Perspectives (1995)

2. D.Liang, General theory on endogenous and exogenous currency. Contemporary economic research,13,2(2009)

3. W.Zou, N.Chen, L.Yang, The influence of central bank communication on market interest rate, Regional finance research, 19,11(2019)

4. F.Ma, C.Hu ,Research on the endogeneity of China's money supply -- An Empirical Analysis Based on the improved model. Exploration of financial theory,21.1(2019)

5. J,Huang, Research on interest rate transmission mechanism of monetary policy and its effectiveness, Journal of Yunnan University of Finance and economics, 55,8(2020)

6. L.ZHOU, Endogenous causes of money supply: a review of domestic and foreign studies. Financial review, 71,5 (2013)

7. H.Yuan, The reconstruction of Keynes' Monetary Thought by levelism and its policy implications. Contemporary economic research,51,1(2021)

8. R.Gracjan, The Post-Keynesian endogenous-money supply: evidence from Poland( 2019)

9. X.Zeng, Endogeneity and exogeneity of interest rate: dialectical relationship and policy implications, Financial theory and practice, 8,4 (2001)

10. J.Li, Duality of Marx's interest theory and contemporary interest rate practice, Contemporary 
economic research, ,7,11(2008)

11. C.Tu, Empirical research on internal and external symbiosis of money supply in China. Guangdong University of Finance and economics, (2014) 